\title{
Do Your Exercises: Reader Participation in Wittgenstein's Investigations
}

ABSTRACT: Many theorists have focused on Wittgenstein's use of examples, but I argue that examples form only half of his method. Rather than continuing the disjointed style of his Cambridge lectures, Wittgenstein returns to the techniques he employed while teaching elementary school. Philosophical Investigations trains the reader as a math class trains a student- 'by means of examples and by exercises’ (\$208). Its numbered passages, carefully arranged, provide a series of demonstrations and practice problems. I guide the reader through one such series, demonstrating how the exercises build upon one another and give us ample opportunity to hone our problem-solving skills. Through careful practice, we learn to pass the test Wittgenstein poses when he claims that something is 'easy to imagine' (\$19). Whereas other critics have viewed the Investigations as merely a diagnosis of our philosophical delusions, I claim that Wittgenstein also writes a prescription for our disease: Do your exercises.

KEYWORDS: practice, active participation, Wittgenstein's method 


\section{Do Your Exercises: Reader Participation in Wittgenstein's Investigations}

Wittgenstein once began a lecture by chastising his audience (quoted in Drury 1984, p.

79):

the hearer is incapable of seeing both the road he is led and the goal which it leads to. That is to say: he either thinks: 'I understand all he says, but what on earth is he driving at?, or else he thinks 'I see what he's driving at, but how on earth is he going to get there?'

Drury (1984) makes a similar complaint about contemporary interpretations of Philosophical Investigations: either Wittgenstein's method is clarified or his goal is made clear-but not both. This breakdown remains as true today as it was 30 years ago. Since Drury's time, Peters and Marshall (1999, p. 189) have articulated Wittgenstein's goal: 'The aim of the great educator is to teach us to think for ourselves.' If we take this as our endpoint, however, we still have to discover the path that leads us there. Many theorists gesture towards the reader's 'active involvement' (Heal 1995, p. 76) in Wittgenstein's text, but their claims are vague and largely unsubstantiated. No one has yet been able to pinpoint the 'fundamentally pedagogical dimension of his philosophy' (Peters and Marshall 1999, p. 169). Although the goal is clear, the path remains murky.

I can shed some light. Whereas other theorists have focused on Wittgenstein's use of examples, I argue that examples form only half of his method. Rather than rehashing his Cambridge lectures, Wittgenstein returns to the techniques he employed during his years as an elementary school teacher. Philosophical Investigations trains the reader like a math class trains a student—-by means of examples and by exercises' (\$208). Its numbered passages, carefully arranged, provide a series of demonstrations and practice problems. I will guide the reader through one such series, demonstrating how the exercises build upon one another and give us 
ample opportunity to hone our problem-solving skills. Through careful practice, we learn to pass the test that Wittgenstein poses when he claims his examples are 'easy to imagine' $(\S 19)$.

At the end of this path, we will be able to say what makes Wittgenstein's method uniquely active and pedagogical. For now, however, let's see where some of my predecessors have gone astray.

\section{Alternative Accounts of Wittgenstein's Method}

Even a cursory glance through the Investigations reveals the originality of Wittgenstein's writing, but his unique style is surprisingly difficult to describe. Many attempts to specify his pedagogical method make the Investigations sound almost commonplace. To give just a few examples: Burbules and Peters (2001, p. 21) discuss Wittgenstein's 'thought experiments,' and Peters and Marshall (1999, p. 175) add a 'vital repertoire of non-argumentational discursive forms — pictures, drawings, analogies, similes, jokes, equations, dialogues with himself, little narratives, questions and wrong answers, thought experiments, gnomic aphorisms, and so on.' Perhaps Wittgenstein is notable for the sheer number of non-discursive forms he uses, but he is far from the first to employ a 'method of philosophical investigation that involves the use of examples' (Savickey 2011, p. 671). Nor is he the only one to master 'the art of asking questions' (Engelmann 1967, p. 115) where 'your answers are suggested or implied and then explained, criticized, or expanded' (Leiber 1997, p. 235-6). Moreover, any cryptic philosopher can lay claim to 'forcing the reader into the work of self-demystification' (Eagleton 1993, p. 9). Thought experiments, rhetorical questions, and diagrams are all popular philosophical tools that Wittgenstein shares with many other authors. None of these methods would make the Investigations a distinctive or uniquely pedagogical text. 
Several of these authors do identify one stylistic feature that separates Wittgenstein from other philosophers: he writes 'dialogues with himself' (Peters and Marshall 1999, p. 175) and ‘imagined interchanges' (Burbules and Peters 2001, p. 21). In addition to being distinctive, dialogues are inherently interactive. Savickey (2011, p. 676) neatly captures this participatory experience: 'The Investigations can be read as a script - one in which we enact, embody, or voice the examples we encounter.' Similarly, Heal (1995, p. 72-3) writes: 'the part of 'you' is to be played by whoever is reading the Investigations. Thus 'you' is me, if I find myself nodding when 'you' speaks... And it is you, if you are similarly willing to join in.' Both these theorists describe how Wittgenstein invites us to participate in his text. Perhaps we have found our pedagogical path?

Savickey and Heal offer a good starting point, but on closer inspection, both descriptions of reader engagement seem oddly passive. Listening to a conversation, following a script, or nodding while someone else speaks require very little activity on the part of the reader. Moreover, as Heal herself points out, all philosophy papers demand this minimal degree of 'active participation' (1999, p. 77). Readers must pay close attention to follow subtle argumentation or parse proofs written in symbolic logic. We must consider counter-examples and objections. We may even find ourselves nodding or shaking our heads. Once again, it is surprisingly difficult to specify what makes Wittgenstein's method uniquely interactive.

This objection leads Heal (1999) to abandon her attempt and turn instead to a therapeutic reading of the Investigations, which focuses on dismantling philosophical puzzles. Savickey (2011, p. 676) goes a few steps further along the theatrical path: she considers the possibility of reading the Investigations as 'improvisational exercises.' As Savickey points out, Wittgenstein often invites us to go beyond the examples he has given, 'to add imaginatively to the variations 
already recorded' (p. 677). She thinks this invitation is key for both the interactive reading experience and Wittgenstein's pedagogical aims: 'When we play out these examples, we become participants (not merely spectators) in the investigation. And once we are participants, these examples aid us in developing our own creativity and conceptual imagination' (p. 677).

Savickey is not alone in following this path. Lesnik-Oberstein (2003, p. 390) also sees the Investigations as training our creative capacities. She highlights the numerous students who feature in Wittgenstein's examples and describes 'the slipping between reader ('you') and 'pupil' ('him'): reader and pupil become one and the same.' We read about students learning to read, and the second personal narration makes us speak in their place. If we step back and consider the 'meta-language' of the Investigations, we find that we, too, are learning a new skill: we are being 'inculcated in 'analogy' (390). Thus, Savickey and Lesnik-Oberstein agree: Wittgenstein teaches us to reproduce 'a certain play of the imagination' (\$216) and create an ever-growing multitude of examples.

This path seems to fulfill our desiderata: the reading experience is both active and pedagogical. Moreover, this interpretation has the advantage of making Philosophical Investigations continuous with Wittgenstein's earlier pedagogical style. As Savickey (1999, p. 3) points out: 'The similarity between his teaching and his writing is striking.' The memoirs of his former students are filled with references to examples and analogies. Gasking and Jackson (1967, p. 50-51) remember: 'The technique was at first bewildering. Example was piled up on example... Always the case was given in concrete detail, described in down-to-earth everyday language.' Another former student, Mays (1967, p. 81), claims that Wittgenstein based his later work directly on lecture notes from this period: 'It never occurred to me then that these notes were destined to become parts of the Philosophical Investigations.' 
Wittgenstein's university lectures featured a pedagogical method like the one Savickey and Lesnik-Oberstein see in the Investigations. Given this overlap, we can use student memoirs to test whether his method had the effect that Savickey and Lesnik-Oberstein propose. We can see if a method based exclusively on examples inspired active participation; if Wittgenstein was satisfied with the results of his method; and most importantly, if he avowed the goal that these later theorist assign to him.

\section{Wittgenstein's Cambridge Lectures}

Student memoirs reveal that Wittgenstein's Cambridge lectures were not very interactive. King (1984, p. 71) speaks of feeling inhibited in Wittgenstein's classes: 'I wished to ask yet feared to do so.' Similarly, Pascal (1984, p. 16) writes: 'He would talk for long periods without interruption, using similes and allegories, stalking about the room and gesticulating. He cast a spell.’ Even Gasking and Jackson (1967, p. 52) agree that class participation was sparse: 'Members of the class would chip in briefly from time to time, though usually to make a suggestion in response to some question which was posed.' This is a mark against the improvisational interpretation of the Investigations. Examples and analogies featured in Wittgenstein's lectures, but his pedagogical method did not foster audience participation.

Nevertheless, his lectures did have the effect that Savickey and Lesnik-Oberstein expected. As Burbules and Peters (2001, p. 16) report: 'It is well known, for example, that he taught in a highly idiosyncratic manner, and that for years after young philosophers at Cambridge mimicked his habits and style.' Students learned to imitate Wittgenstein's style of doing philosophy. They would conduct grammatical investigations through concrete examples. Wittgenstein's method taught them to reproduce his analogies and to 'add imaginatively to the variations already recorded,' just as Savickey argued it would (2011, p. 677). 
Wittgenstein, however, was not pleased with these results. In Culture and Value (1980, p.

38), he agonizes over the possibility that he is merely teaching his students to mimic his philosophical style:

A teacher may get good, even astounding, results from his pupils while he is teaching them and yet not be a good teacher; because it may be that, while his pupils are directly under his influence, he raises them to a height which is not natural to them, without fostering their own capacities for work at this level, so that they immediately decline again as soon as the teacher leaves the classroom. Perhaps this is how it is with me; I have sometimes thought so.

Peters and Marshall (1999, p. 179) discuss Wittgenstein's worries, but quickly dismiss his doubts with a quote from his friend, Britton: 'He said that many of his pupils merely put forward his own ideas: and that many of them imitated his voice and manner; but that he could easily distinguish those who really understood.' Other friends of Wittgenstein were less sanguine about the effect he had upon his students. As von Wright (1967, p. 26) records: 'He thought that his influence as a teacher was, on the whole, harmful to the development of independent minds in his disciples. I am afraid that he was right.' Similarly, Pascal (1984, p. 33) laments: 'Alas, he was no pedagogue.'

My aim is not to settle whether Wittgenstein was an effective teacher. I only wish to call attention to the form that his doubts about his teaching took. He feared his students would learn to imitate his method, rather than developing their own capacities for independent thought. This anxiety poses a problem for the improvisational interpretation. Wittgenstein worried that his students would mimic his style, so we can conclude: he wanted his students to learn something else. Therefore, Wittgenstein's pedagogical method must be something more substantive than 'improvisational exercises' that teach us to mimic his mannerisms. His goal—and the path he takes to reach it-lies elsewhere. 


\section{A New Approach: Wittgenstein's Classroom}

Wittgenstein is not repeating his Cambridge lectures; instead, he returns to the methods he employed as a schoolteacher in Austria. The Investigations is filled with examples of students learning to calculate (§143-55), to read (§156-71), and to perform numerous other skills we are 'all taught at elementary school’ (\$351). Many theorists agree that these vignettes are drawn from Wittgenstein's time as a schoolteacher (Engelmann 1967; Savickey 1999; Peters and Marshall 1999). I go one step further. Wittgenstein not only describes how he taught his students; he simultaneously demonstrates the methods he is using to teach us, his readers. Whereas Wittgenstein's university students were silent and afraid, his elementary students were 'climbing over each other in their eagerness to be given a chance to answer or to demonstrate a point' (Hermione Wittgenstein 1984, p. 5). Bartley (1985, p. 100) recounts Wittgenstein's 'stunning results in mathematics, teaching ten- and eleven-year-old boys advanced algebra and geometry.' Even his critics described him as an 'excellent educator' whose 'teaching objectives overshot the marks prescribed for the elementary school level' (Kund, quoted in Hargrove 1980, p. 457). Moreover, Wittgenstein—who, as we've seen, was not inclined to brag about his teaching - felt so confident in his technique that he compiled a textbook for use in other rural classrooms. He boasts (1993, p. 19): 'the improvement of spelling was astonishing. The orthographic conscience had been awakened!'

How did Wittgenstein achieve these extraordinary results? Rigorous practice. He devoted 'the first two hours of each morning' to mathematical instruction (Monk 1990, p. 195); he spent 'several months' teaching his students how to spell (Wittgenstein 1993, p. 19). Instead of lecturing, he demanded student participation. As Monk (1990, p. 195) emphasizes, 'practical exercises played a large part in his teaching': 
The children were taught anatomy by assembling the skeleton of a cat, astronomy by gazing at the sky at night, botany by identifying plants on walks in the countryside, architecture by identifying building styles during an excursion to Vienna.

Similarly, Bartley (1985, pp. 99-100) describes one of these excursions:

While they wandered through the streets of Vienna he threw a barrage of questions and information at them, calling their attention to machines, architectural styles, or other things they had already learned about at school. For instance, at the Technical Museum the children had to explain the models of steam engines, block-and-tackle, pulleys, and other mechanisms by reference to what they had studied in class.

These accounts reveal a pedagogical method that is interactive and highly effective. The students were asked to apply the concepts they had learned in class to new cases. These 'practical exercises' forced students to practice their skills and test their knowledge.

Taking Wittgenstein's classroom techniques as our model, we can now return to Philosophical Investigations. We'll find that this text, too, contains a series of exercises.

\section{Exercises in Philosophical Investigations}

Of course, I am not the first to use the term 'exercise' to describe Wittgenstein's method. As noted above, Savickey (2011, p. 676) compares the Investigations to 'improvisational exercises... in which we enact, embody, or voice the examples we encounter.' I will follow Savickey in highlighting the active nature of these exercises. Whereas she has theatrical exercises in mind, however, I take mathematical exercises as my model. Like a math teacher, Wittgenstein assigns exercises to test our understanding and allow us to practice the skills we've learned in previous sections. By completing these problem sets, we master the techniques and concepts that are presupposed by later passages.

Sometimes, Wittgenstein explicitly assigns these problem sets. For instance, $§ 182$ is almost indistinguishable from a homework assignment in a grammar workbook:

The grammar of "to fit", "to be able" and "to understand". Exercises: (1) When is a cylinder C said to fit into a hollow cylinder H? Only as long as C is inside H? (2) Sometimes one says 
that: $\mathrm{C}$ has ceased to fit into $\mathrm{H}$ at such-and-such a time. What criteria are used in such a case for its having happened at that time? ... (5) Someone asks me, "Cay you life this weight?" I answer, "Yes". Now he says, "Do it!" - and I can't. In what kind of circumstances would one accept the excuse "When I answered 'yes' I could do it, only now I can't"?

Baker and Hacker (2005, p. 353) provide solutions to these exercises, so I will not work through them methodically here. Notice, however, that all these exercises involve imagining a situation in some detail. You read through a phrase like ' $\mathrm{C}$ has ceased to fit into $\mathrm{H}$,' and then you are asked to imagine the kinds of circumstances in which those words would be appropriate to say. The reader is forced to supply the missing context that makes the phrase make sense. Perhaps $\mathrm{C}$ is rolled up bread dough that has expanded in the oven until it no longer fits in its packaging, or maybe $\mathrm{H}$ is the sleeve of a sweater that has shrunk in the wash until it no longer fits your arm. As Baker and Hacker (2005, p. 353) point out: 'Many variants can be imagined.' Don't just read my answers; come up with your own solutions! Wittgenstein presents these exercises as problems that must be solved before the reader can continue. By completing them, you'll discover for yourself: 'The criteria which we accept for 'fitting', 'being able to', 'understanding', are much more complicated than might appear at first sight' $(§ 182)$.

Often, Wittgenstein is less explicit about assigning these problem sets. For example, in $\S 27$, he gives a similar series of tasks without labeling them 'exercises':

in fact we do the most various things with our sentences. Think just of exclamations, with their completely different functions.
Water!
Away!
Ow!
Help!
Splendid!
No!

Are you still inclined to call these words "names of objects"?

Baker and Hacker (2005, p. 91) answer the question: 'The range of speech activities is manifold. This is true even of one-word exclamations.' However, they gloss over the process that leads us 
to this conclusion. Here, as previously, Wittgenstein proceeds by listing phrases and asking us to think about the contexts in which each of them would be appropriate. Ask yourself: why would you exclaim 'Water!'? Is there a fire, or are you whispering the order because your throat is so parched? What about 'Splendid!'? Do you find yourself smiling, or are you rolling your eyes sarcastically? Do you cringe in fear while you shout 'Help!' or are you giggling as you imagine being tickled? I don't know how you'll interpret these exclamations - but you do, if you've done your exercises. So only you can answer Wittgenstein's final question: ‘Are you still inclined to call these words “names of objects”?’ (\$27).

Thus far, I've focused on mental exercises that deepen our understanding of our linguistic practices, but some exercises diverge significantly from this model. In $\S 33$, for instance, Wittgenstein gives us an action to perform:

And what does 'pointing at the shape', 'pointing at the colour', consist in? Point at a piece of paper. - And now point at its shape - now at its colour - now at its number (that sounds odd). - Well, how did you do it? - You'll say that you 'meant' something different each time you pointed. And if I ask how that is done, you'll say you concentrated your attention on the colour, the shape, and so on. But now ask again: how is that done?

Baker and Hacker (2005, p. 107) claim that in this section 'W[ittgenstein] asks us to reflect on what counts as pointing to the colour rather than to the shape or the number.' I disagree. I don't think Wittgenstein is asking us to reflect on what counts as pointing; I think he is asking us, quite literally, to point. We're reading his Investigations. Therefore, we have a piece of paper in front of us. Without even closing the book, we can follow his directions: point at the paper, its shape, its color, and even its number. Only afterwards are we encouraged to reflect on our actions, when Wittgenstein asks: 'Well, how did you do it?' Viewed this way, we begin to see the uniquely participatory demands of Wittgenstein's text. First we perform the physical actions; then we 
complete the rest of the exercise. Like the children in Wittgenstein's classroom, we must do our own work.

Now that we have some idea of what to look for, let's try a more difficult problem set: exercises that are-Wittgenstein claims—-easy to imagine’ (§19).

\section{5. 'Easy to Imagine'}

Garver (1990, p. 180) alerts us to the problematic nature of these passages: 'I have regularly stumbled over these passages because I am unable to imagine what Wittgenstein says one can "easily” imagine.' Baker and Hacker (2005) share this worry. When Wittgenstein claims in $\$ 19:$ 'It is easy to imagine a language consisting only of orders and reports in battle,' Baker and Hacker write (p. 73):

$\mathrm{W}$ [ittgenstein] is arguably too hasty here. Is it really possible to imagine a society, and a form of life, sufficiently well organized to engage in battle and to give orders and reports in battle - and to have no other uses for words? How would this language be taught to children? How are we to envisage a use for orders or reports in battle, but no use for the same forms of words outside a battle?

These are legitimate questions. Initially, it seems impossible to conceive of such a language, and even if we did ultimately succeed, we would need to invest a great deal of careful thought before we could answer Baker and Hacker's questions. How can Wittgenstein claim that 'it is easy'? Perhaps it is easy for him to imagine these cases, but does he expect it to be easy-or even possible-for us to do so?

I think he does. Moreover, I think his demand is perfectly reasonable. $\S 19$ is a test: at this point in the text, you should be able to imagine a language comprised entirely of orders and reports in battle. I am not claiming that Wittgenstein expects us to already have this ability before we begin reading the Investigations; the challenge appears in $\S 19$, not in $\S 1$. Rather, I am claiming that Wittgenstein is assigning an exercise to see if we've been paying attention to the 
previous 18 sections. If we stumble over $§ 19$, we should do what all student should do when faced with a problem that they don't know how to solve - turn back to the beginning of the chapter and review the relevant skills.

In this case, the relevant skill is imagining a primitive language. Wittgenstein begins to teach us this skill in $\S 2$ :

Let us imagine a language for which the description given by Augustine is right: the language is meant to serve for communication between a builder A and an assistant B. A is building with building stones: there are blocks, pillars, slabs and beams. B has to pass him the stones and to do so in the order in which A needs them. For this purpose they make use of a language consisting of the words "block", "pillar", "slab", "beam". A calls them out; B brings the stone which he has learnt to bring at such-and-such a call. - Conceive of this as a complete primitive language.

Notice that Wittgenstein says, 'let us imagine.' Like a math teacher working through practice problems on the board, he teaches us how to imagine a primitive language by working through these early problems along with us.

The first difficulty we might have is one Garver (1990, p. 181) articulates: 'I have trouble conceiving whether creatures whose use of language is so constrained would really be speaking a language, or would still be human beings.' Like any good teacher, Wittgenstein has anticipated such a reasonable objection. In $\S 3$, he shows us how to overcome this difficulty. Immediately after he asks us to 'conceive of this as a complete primitive language,' Wittgenstein clarifies his request: he is using 'language' to 'describe a system of communication; only not everything that we call language is this system.' Like the word 'remainder' in long division, 'language' is being used in a specialized way during these exercises. Thus, the task is easier than we might at first suppose. Wittgenstein is asking us to imagine what Baker and Hacker (2005, p. 55) call a 'protolanguage' - a primitive form of communication that lacks many of the features we tend to associate with more complex languages, like syntax or truth conditions. We wouldn't be able to 
use this kind of proto-language to debate political issues or bet on a wrestling match; but calland-response works well enough if we are building with blocks. Although we might-like Garver (1990) — initially deny that the builders 'would really be speaking a language,' we should be able to conceive of their interaction as a simpler form of communication. Similarly, when we look ahead to $§ 19$, it should be easier to 'imagine a language consisting only of orders and reports in battle' if we imagine the call-and-response between a war chief and a warrior as a proto-language akin to the one in $\S 2$. Before we can complete the assignment, we must first understand the vocabulary.

We might also make the task more difficult for ourselves if we import later concepts into these preliminary exercises. Garver (1990, p. 181) gives a good example of this kind of mistake. When he discusses other scholars who struggle with $\S 2$, he says of Rhees:

He does not explicitly mention form of life, but it is clear that one of the reasons he finds it difficult to conceive the verbal signals of the builders as a language is that he has difficulty imagining their form of life.

'Form of life' is a contentious topic, and if Wittgenstein were claiming that it was easy to imagine an entire way of living centered around such a limited use of language, Rhees and Garver would be justified in their objections. At this point, however, Wittgenstein has not yet introduced the term 'form of life.' In fact, he does not introduce this concept until partway through $§ 19$ - after he assigns the test of imagining 'a language that consists only of orders and reports in battle.' Thus, our confusion about its definition should not prevent us from completing the exercises assigned here. Instead of being distracted by future problems, we should stay focused on the task at hand. $§ 5$ further clarifies the structure of these early exercises:

the general concept of the meaning of a word surrounds the working of language with a haze which makes clear vision impossible. - It dispenses the fog if we study the phenomena of language in primitive kinds of use in which one can clearly survey the purpose and functioning of the words. 
A child uses such primitive forms of language when he learns to talk.

Like children learning a new skill, we are 'studying' 'primitive kinds of use.' Wittgenstein is not asking us to come up with an explanation of how these proto-languages evolved or a realistic depiction of the day-to-day lives of the society that speaks them. At this point, the builders may be anything from imaginary proto-humans to toddlers playing with blocks. We shouldn't confuse the issue by skipping ahead in the textbook; we should complete the exercises in the order they were assigned.

Even if we avoid these misinterpretations, however, we might still have trouble completing the exercise assigned in $§ 19$. If we accept the claim in $\S 5$ that 'a child uses such primitive forms of language' then the next natural question is the one Baker and Hacker (2005, p. 73) ask about $§ 19:$ 'How would this language be taught to children?' Wittgenstein responds directly to this worry. In $\S 6$ he describes how a proto-language would be taught to children:

We could imagine that the language of $\S 2$ was the whole language of $\mathrm{A}$ and $\mathrm{B}$, even the whole language of a tribe. The children are brought up to perform these actions, to use these words as they do so, and to react in this way to the words of others.

An important part of the training will consist in the teacher's pointing to the objects, directing the child's attention to them, and at the same time uttering a word; for instance, the word "slab" as he displays that shape.

Once again, in this section Wittgenstein introduces a practice problem, and he works through it with us: 'We could imagine that the language of $\S 2$ was... the whole language of a tribe.' In order to imagine a tribe like the builders we have to start with precisely the problem that Baker and Hacker have raised—we must begin by imagining how the language would be taught. In $§ 7$ Wittgenstein further elaborates his answer:

In the practice of the use of language (2) one party calls out the words, the other acts on them. However, in instruction in the language the following process will occur: the learner names the objects; that is, he utters the word when the teacher points at the stone. - Indeed, there will be an even simpler exercise: the pupil repeats the words after the teacher - both of these being speech-like processes. 
If we apply this same technique to $§ 19$, we can begin to describe how trainees would be taught a language 'consisting only of orders and reports in battle.' When the language is practiced on the battlefield, the war chief calls out the words and the warrior acts on them. When the language is taught to new recruits, however, the words would be used in a different way. The chief would point to an object — a club, a captured enemy — and say a word. The recruits would repeat the word after the chief. Later, they would learn to follow orders - swing the club, hit the enemyand to report on the success or failure of their mission: 'The enemy is running away' or '10 of our warriors were captured.'

Wittgenstein considers one final impediment. Perhaps, like Garver (1990, p. 180), we are unable to "imagine the "language" of the two builders in PI 2 as the whole language of those people.' Wittgenstein teaches us to overcome this difficulty in $§ 18$ :

Don't let it bother you that languages (2) and (8) consist only of orders. If you want to say that they are therefore incomplete, ask yourself whether our own language is complete - whether it was so before the symbolism of chemistry and the notation of the infinitesimal calculus were incorporated in to it; for these are, so to speak, suburbs of our language. (And how many houses or streets does it take before a town begins to be a town?)

Here Wittgenstein assigns us a set of optional exercises. If we are having trouble conceiving of a proto-language as a 'complete' language, then we should ask ourselves the follow questions: (1) Is our own language complete? (2) Was it complete before the symbolism of chemistry or the notation of infinitesimal calculus? (3) Think of our language as a city and these additions as suburbs: how many houses or streets does it take before a town begins to be a town? (How far does a system of communication have to extend before it counts as a complete system?) Baker and Hacker (2005, p. 72) give the solution to these optional exercises:

That a language can be extended does not show it to be incomplete prior to its extension. If the possibility of extending a language proved that it was incomplete, there would be no such 
thing as a language that was not incomplete, and hence the phrase 'incomplete language' would be meaningless.

Just as our language was not incomplete before we could discuss calculus or chemistry, a protolanguage is not incomplete merely because it is limited to a particular type of interaction.

Returning to $\S 19$, we should not be bothered by the fact that a proto-language consists 'only of orders and reports.' If we've already accepted that the builders' language is complete, then a language that contains both commands and assertions should be relatively easy to imagine.

Now we can see how $§ 19$ is a test. Wittgenstein is employing the same techniques he used to teach his elementary school students (Bartley 1985, p. 100):

at the Technical Museum [in Vienna] the children had to explain the models of steam engines, block-and-tackle, pulleys, and other mechanisms by reference to what they had studied in class. In Trattenbach, Wittgenstein had taught his pupils the laws of the lever; now he asked them to apply those laws to specific examples.

Similarly, we are asked to imagine the specific examples in $\S 19$ by reference to what Wittgenstein has already taught us in the opening sections of the Investigations. He has demonstrated the techniques we must apply in order to imagine this new case. Once we've worked carefully through $\S \S 2-18, \S 19$ will no longer pose a problem for us: 'It [should be] easy to imagine a language consisting only of orders and reports in battle. - Or a language consisting only of questions and expressions for answering Yes and No - and countless other things.' I've worked through the first example. With the same tools we can solve the remaining problemsbut I leave these as exercises for the reader.

\section{Conclusion}

The method I have outlined captures the 'fundamentally pedagogical dimension' (Peters and Marshall 1999, p. 173) of Wittgenstein's Philosophical Investigations: the reader must work through the assigned exercises. In fact, Wittgenstein makes the same claim. In an early draft 
(1998, p. 64), Wittgenstein wrote: 'This book could be called a textbook. But not a textbook in that it imparts knowledge, rather in that it stimulates thinking' (my translation). Since Wittgenstein could not teach the class in person, he left behind a textbook that enables us to teach ourselves. 


\section{References}

Baker, G.P, \& Hacker, P.M.S. (2005). Wittgenstein: understanding and meaning, Part II. Oxford: Blackwell Publishing.

Bartley, W.W. (1985). Wittgenstein. LaSalle, IL: Open Court.

Burbules, N.C., \& Peters, M. (2001). Ludwig Wittgenstein: 1889-1951. In J.A. Palmer (ed.), Fifty modern thinkers on education: from Piaget to the present day (pp. 15-23). London: Routledge.

Drury, M.O’C. (1984). Some notes on conversations with Wittgenstein. In R. Rhees (ed.), Recollections of Wittgenstein (pp. 76-96). Oxford: Oxford University Press.

Eagleton, T. (1993). Wittgenstein: the Terry Eagleton script. London: BFI Publishing.

Engelmann, P. (1967). Letters from Ludwig Wittgenstein, with a memoir. Oxford: Basil Blackwell.

Garver, N. (1990). Form of life in Wittgenstein's later work. Dialectica. 44(1-2), 175-201. Gasking, D.A.T., \& Jackson, A.C. (1967). Wittgenstein as a teacher. In K.T. Fann (ed.), Ludwig Wittgenstein: the man and his philosophy (pp. 49-55). New York: Dell Publishing Co.

Hargrove, E.C. (1980). Wittgenstein, Bartley, and the Glöckel school reform. Journal of the History of Philosophy. 18(4), 453-61.

Heal, J. (1995). Wittgenstein and dialogue. In T.J. Smiley (ed.), Philosophical dialogues: Plato, Hume, Wittgenstein (pp. 63-83). Oxford: Oxford University Press.

King, J. (1984). Recollections of Wittgenstein. In R. Rhees (ed.), Recollections of Wittgenstein (pp. 68-75). Oxford: Oxford University Press.

Leiber, J. (1997). On what sort of speech act Wittgenstein's Investigations is and why it matters. The Philosophical Forum. 28(3), 232-67. 
Lesnik-Oberstein, K. (2003). The Philosophical Investigations' children. Educational Philosophy and Theory. 35(4), 381-394.

Mays, W. (1967). Recollections of Wittgenstein. In K.T. Fann (ed.), Ludwig Wittgenstein: the man and his philosophy (pp. 79-88). New York: Dell Publishing Co.

Monk, R. (1990). Ludwig Wittgenstein: the duty of genius. London: Jonathan Cape.

Pascal, F. (1984). Wittgenstein: A personal memoir. In R. Rhees (ed.), Recollections of Wittgenstein (pp. 12-49). Oxford: Oxford University Press.

Peters, M., \& and Marshall, J. (1999). Wittgenstein: philosophy, postmodernism, pedagogy. London: Bergin \& Garvey.

Savickey, B. (1999). Wittgenstein's art of investigation. London: Routledge.

Savickey, B. (2011). Wittgenstein's use of examples. In O. Kuusela \& M. McGinn (eds.), The Oxford handbook of Wittgenstein (pp. 667-696). Oxford: Oxford University Press.

von Wright, G.H. (1967). A biographical sketch. In K.T. Fann (ed.), Ludwig Wittgenstein: the man and his philosophy (pp. 13-29). New York: Dell Publishing Co.

Wittgenstein, H. (1984). My brother Ludwig. In R. Rhees (ed.), Recollections of Wittgenstein (pp. 1-11). Oxford: Oxford University Press.

Wittgenstein, L. (1993). Preface to the Dictionary for Elementary Schools. In Philosophical occasions: 1912-1951. (Trans: Klagge J.C. \& Nordmann, A.). Indianapolis: Hackett.

Wittgenstein, L. (1998). MS 119. Wittgenstein's Nachlass: the Bergen electronic edition. Oxford University Press. http://www.nlx.com/collections/124. Accessed 30 January 2016.

Wittgenstein, L. (1980). Culture and Value. (Trans: Winch, P.). Oxford: Basil Blackwell. Wittgenstein, L. (2009). Philosophical Investigations. (Trans: Anscombe, G.E.M., Hacker, P.M.S., \& Schulte, J.). Oxford: Wiley-Blackwell. 